\title{
Human step II splicing factor hSlu7 functions in restructuring the spliceosome between the catalytic steps of splicing
}

\author{
Katrin Chua and Robin Reed ${ }^{1}$ \\ Department of Cell Biology, Harvard Medical School, Boston, Massachusetts 02115 USA
}

\begin{abstract}
The spliceosome catalyzes pre-mRNA splicing in two steps. After catalytic step I, a major remodeling of the spliceosome occurs to establish the active site for step II. Here, we report the isolation of a cDNA encoding hSlu7, the human homolog of the yeast second step splicing factor Slu7. We show that hSlu7 associates with the spliceosome late in the splicing pathway, but at a stage prior to recognition of the $3^{\prime}$ splice site for step II. In the absence of hSlu7, splicing is stalled between the catalytic steps in a novel complex, the $\mathrm{C}_{\Delta \mathrm{hSlu}}$ complex. We provide evidence that this complex differs significantly in structure from the known spliceosomal complexes, yet is a functional intermediate between the catalytic steps of splicing. Together, our observations indicate that hSlu7 is required for a structural alteration of the spliceosome prior to the establishment of the catalytically active spliceosome for step II.
\end{abstract}

[Key Words: Pre-mRNA splicing; splicing factor; catalytic step II; spliceosome; hSlu7]

Received December 21, 1998; revised version accepted February 16, 1998.

The two catalytic steps of the pre-mRNA splicing reaction take place in the spliceosome, a dynamic complex of snRNAs and a large number of proteins (for reviews, see Moore et al. 1993; Kramer 1996; Reed and Palandjian 1997; Will 1997). In catalytic step I, the branch site adenosine carries out a nucleophilic attack on the $5^{\prime}$ splice site, generating the splicing intermediates (exon 1 and lariat-exon 2). In catalytic step II, the free hydroxyl group on exon 1 attacks the $3^{\prime}$ splice site to generate spliced mRNA and the excised lariat intron. Both transesterifications are thought to be mediated by snRNAs, but proteins play integral roles in configuring the active sites for catalysis.

The catalytic center of the spliceosome for step I is established after a series of spliceosomal complexes assembles on pre-mRNA in the order E, A, B, and C (for reviews, see Moore et al. 1993; Reed and Palandjian 1997). U1 snRNP recognizes the $5^{\prime}$ splice site in the E complex, and U2 snRNP recognizes the branchpoint sequence (BPS) in the A complex. In the B complex, a trisnRNP particle consisting of U4, U5, and U6 snRNPs replaces U1 snRNP at the 5 ' splice site. Prior to catalytic step I, U4 snRNP is released (Pikielny et al. 1986; Cheng and Abelson 1987; Lamond et al. 1988; Yean and Lin 1991) and an interaction between U2 and U6 snRNPs positions the branch site adenosine for attack at the $5^{\prime}$

${ }^{1}$ Corresponding author.

E-MAIL rreed@hms.harvard.edu; FAX (617) 432-3091. splice site (Madhani and Guthrie 1994). The catalytically active spliceosome for both steps of the splicing reaction is referred to as the C complex, which is detected on native gels as a discrete band. However, different configurations of the $\mathrm{C}$ complex must exist because the two transesterifications involve different reactive groups (for reviews, see Moore et al. 1993; Staley and Guthrie 1998). In addition, between steps I and II, a rearrangement occurs that repositions U5 snRNP to contact the region between the BPS and the AG dinucleotide (Umen and Guthrie 1995a; Chiara et al. 1997). This interaction may play a role in specifying the AG that serves as the $3^{\prime}$ splice site. U5 snRNP is also thought to align exons 1 and 2 for ligation (for review, see Newman and Norman 1992). Here, we refer to the catalytically active step I spliceosome as the $\mathrm{C}_{\mathrm{I}}$ complex and the catalytically-active step II spliceosome as the $\mathrm{C}_{\mathrm{II}}$ complex.

A great deal of insight into the mechanism of step II has come from studies in yeast (for review, see Umen and Guthrie 1995c). The proteins Prp16 (Couto et al. 1987; Burgess et al. 1990; Schwer and Guthrie 1991), Prp17 (Vijayraghavan et al. 1989; Jones et al. 1995), Prp18 (Vijayraghavan and Abelson 1990; Horowitz and Abelson 1993), and Slu7 (Frank and Guthrie 1992; Ansari and Schwer 1995; Jones et al. 1995) function exclusively in step II, and Prp8 functions in both step I and step II (Brown and Beggs 1992; Teigelkamp et al. 1995; Umen and Guthrie 1995a,b). Prp22, a protein involved in the release of spliced mRNA, also plays a role in step II 
(Schwer and Gross 1998). In yeast, two different stages between the catalytic steps can be distinguished on the basis of their ATP requirements (for review, see Umen and Guthrie 1995c). After catalytic step I, Prp16 and Prp17 function first in a ATP-dependent stage (Schwer and Guthrie 1991,1992; Ansari and Schwer 1995; Jones et al. 1995), and Prp16 can be UV cross-linked to a 15nucleotide RNase $\mathrm{T} 1$ digestion product containing the $3^{\prime}$ splice site (Umen and Guthrie 1995b). Subsequently, Slu7, Prp18, and Prp22 function in an ATP-independent stage (Horowitz and Abelson 1993; Ansari and Schwer 1995; Jones et al. 1995; Schwer and Gross 1998), and Slu7 and Prp8 can be UV cross-linked to the RNA at the $3^{\prime}$ splice site (Umen and Guthrie 1995b). Slu7, Prp18, and Prp22 are dispensable for use of $3^{\prime}$ splice sites located near the branch site $<12,12$, and 21 nucleotides, respectively), but are required for use of more distant 3 ' splice sites (Frank and Guthrie 1992; Brys and Schwer 1996; Zhang and Schwer 1997). Therefore, these proteins are thought to play a role in bringing distant $3^{\prime}$ splice sites into the spliceosome's active site for catalytic step II. Although the UV cross-linking experiments indicate that Slu7 contacts the $3^{\prime}$ splice site, this region of the pre-mRNA is dispensable for the association of Slu7 with the spliceosome (Brys and Schwer 1996).

In humans, homologs of the step II factors Prp16, Prp17, and Prp18 have been identified shown to be general step II splicing factors (Horowitz and Krainer 1997; Ben Yehuda et al. 1998; Lindsey and Garcia-Blanco 1998; Zhou and Reed 1998). Thus, splicing factors important for step II are conserved from yeast to humans. To gain further insight into the mechanism of step II, we identified and characterized the human homolog of Slu7. We show that hSlu7 is first detected in purified spliceosomes concomitant with the products of catalytic step I. The association of hSlu7 with the spliceosome occurs before the AG dinucleotide and the adjacent pyrimidine tract at the 3 ' splice site are recognized for step II. Significantly, extracts depleted of hSlu 7 are blocked before step II and accumulate the products of step I in a novel spliceosomal complex, the $\mathrm{C}_{\Delta \mathrm{hSlu}}$ complex. We provide evidence that this $\mathrm{C}_{\Delta \mathrm{hslu}}$ complex is a functional precursor to the catalytically active $\mathrm{C}_{\mathrm{II}}$ complex. Thus, the $\mathrm{C}_{\Delta \mathrm{hSlu} 7}$ complex defines a new stage between catalytic steps I and II of splicing.

\section{Results}

\section{Isolation of a cDNA encoding hSlu 7}

A partial human cDNA with homology to Slu7 (Frank and Guthrie 1992) was identified in a BLAST search of expressed sequence tags (ESTs) and a full-length cDNA obtained by PCR strategies (see Materials and Methods). This cDNA (1758 bp) encodes a 586-amino-acid protein, with a predicted molecular weight of $68 \mathrm{kD}$ (Fig. 1A). We have designated this protein hSlu7. To characterize hSlu7, we expressed a GST-hSlu7 fusion protein in Escherichia coli and raised rabbit polyclonal antisera against it. These antisera detect a major band of $\sim 70 \mathrm{kD}$ on West-

A MSATYVDAVN AAPLSGSKEM SLEEPKKMTR EDWRKKKELE EORKLGNAPA 50 EVDEEGKDIN PHIPQYISSV PWYIDPSKRF TLKHORPQPE KOKOFSSSGE 100 WYKRGYKENS IITKYRKGAC ENCGAMTHKK KDOFERPRRV GAKFTGTNIA 150 PDEHVQPQLM FDYDGKRDRW NGYNPEEHMK IVEEYAKVDL AKRTLKAOKL 200 QEELASGKLY EOANSPKHOW GEEEPNSUTE KDHNSEDEDE DKYADDIDMP 250 GUNFDSKRRI TVRNLRIRED IAKYLRNLDF NSAYYDPKTR AMRENFYANA 300 GKNPDEVSYA GONFVRYTGD TISMAOTOLF AWEAYDKGSE VHLOADPTKL 350 ELLYKSFKVK KEDFKEOOKE SILEKYGGQE HLDAPPAELL LAQTEOYVEY 400 SRHGTVIKGQ ERAVACSKYE EDVKIHNHTH IWGSYWKEGR WGYKCCHSFF 450 KYSYCTGEAG KEIVNSEEC I INEITGEESV KKPOTLMELH OEKLKEEKKK 500 KKKKKKKHRK SSSDSDDEEK KHEKLKKALN AEEARLLHYK ETMOIDERKR 550 PYNSMYETRE PTEEEMEAYR MKRQRPDDPM ASFLGO

B

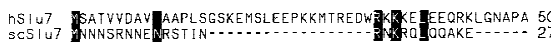

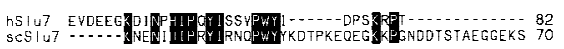

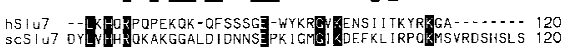

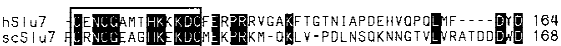

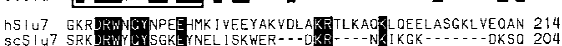

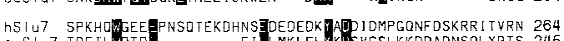

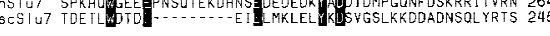

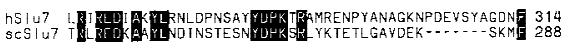

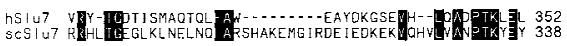

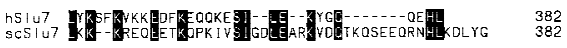

Figure 1. (A) Predicted amino acid sequence of hSlu7. The 1758-bp cDNA sequence of the hSlu7 gene has been deposited in the DDBJ/EMBL/GenBank database under accession no. AF101074. The zinc knuckle motif is boxed. $(B)$ Alignment of the 382-amino-acid yeast Slu7 protein (scSlu7) with the aminoterminal 382 amino acids of hSlu7. Alignments were done by the Clustal method. Identical residues are shaded, and the zinc knuckles are boxed. $(C)$ hSlu7 detected on a Western blot of nuclear extract comigrates with hSlu 7 generated by in vitro translation of the hSlu7 cDNA.

ern blots of total nuclear extracts, and this band comigrates with in vitro-translated hSlu7 (Fig. 1C). This observation and the fact that an upstream stop codon precedes the designated initiator methionine indicate that the hSlu7 cDNA encodes a full-length protein. hSlu7 is 204 amino acids longer than yeast Slu7 (Fig. 1B). The amino-terminal two-thirds of the human protein aligns with Slu7, where the identity is $24 \%$ (Fig. 1B). The highest similarity is a zinc knuckle (boxed, Fig. 1A, B), a motif present in retroviral nucleocapsid proteins and several splicing factors (Frank and Guthrie 1992; Cavaloc et al. 1994; Arning et al. 1996; Abovich and Rosbash 1997).

The hSlu7 amino acid sequence was used to search the GenBank database. In addition to Slu7, this search identified a Caenorhabditis elegans and an Arabidopsis thaliana ORF, both of which are $41 \%$ identical to hSlu7 (data not shown). Because Slu7 is the only protein in the Saccharomyces cerevisiae genome with any significant homology to hSlu7 and because of the functional similarities between hSlu7 and Slu7 (see below), we conclude that the two proteins are orthologs.

\section{hSlut joins the spliceosome late in the splicing pathway}

To determine when hSlu7 associates with the spliceosome, we carried out a time course of spliceosome assembly. Spliceosomes were assembled on adenovirus 
major late (AdML) pre-mRNA for 15, 25, 35, and $45 \mathrm{~min}$ and then isolated by gel filtration and affinity chromatography. Analysis of the RNA and protein components of the complexes is shown in Figure 2. The RNA products of catalytic step I are first detected at $25 \mathrm{~min}$, and the step II products are detected at $35 \mathrm{~min}$ (Fig. 2A). Western blots of the spliceosomal complexes isolated at each time point were probed with antibodies to hSlu7. hSlu7 is first detected at $25 \mathrm{~min}$, concomitant with the appearance of the splicing intermediates (Fig. 2, cf. B with A). In contrast, the U2 snRNP component SAP 130, which is known to first associate early in spliceosome assembly (Bennett et al. 1992), is detected at constant levels throughout the time course (Fig. 2B). This association of hSlu7 with late spliceosomal complexes occurs generally, because hSlu7 is detected in spliceosomes assembled on different pre-mRNA substrates, including AdML, $\alpha$-tropomyosin $(\alpha-\mathrm{TM}$; Fig. 2C,D), and Fushi tarazu (Ftz; data not shown).

The kinetics and efficiency of splicing vary with different pre-mRNA substrates. In contrast to AdML premRNA, the products of step I are not detected until the 45 min time point with $\alpha$-TM pre-mRNA (Fig. 2C), and spliced mRNA is barely detectable by $60 \mathrm{~min}$ (Fig. 2C). Significantly, hSlu7 is not detected in these spliceo-
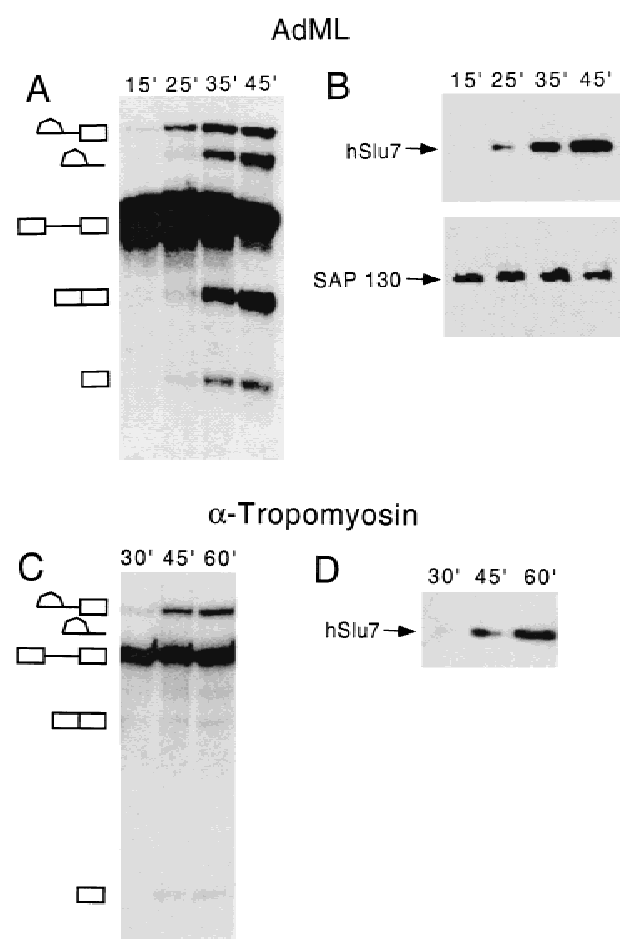

Figure 2. hSlu7 associates with the spliceosome late in the splicing pathway. Spliceosomes were assembled on AdML $(A, B)$ or $\alpha$-TM $(C, D)$ pre-mRNA for the indicated times and then purified. $(A, C)$ Total RNA isolated from an aliquot of the gel filtration fractions was fractionated on a $15 \%$ denaturing polyacrylamide gel. Splicing products and intermediates are indicated. $(B, D)$ Western blots of total protein isolated from spliceosomal complexes in $A$ and $C$, probed with antibodies to the indicated proteins. somes until the 45 min time point, concomitant with step I. Thus, on both AdML and $\alpha$-TM pre-mRNAs, hSlu7 is first detected in purified spliceosomes when the products of step I first appear. Together, these observations suggest that the association of hSlu7 with the spliceosome is coupled to catalysis of step I.

\section{The pyrimidine tract and $A G$ dinucleotide are dispensable for association of hSlu 7 with the spliceosome}

The AG dinucleotide at the 3 ' splice site functions in step II of splicing (Reed and Maniatis 1985; Aebi et al. 1986). To determine whether this sequence element is required for the association of hSlu7 with the spliceosome, we isolated spliceosomes assembled on an AdML pre-mRNA containing an AG $\rightarrow$ GG mutation at the $3^{\prime}$ splice site (Gozani et al. 1994). This mutation specifically blocks catalytic step II (Fig. 3B; cf. with wild type in Fig. 2A). However, as shown in Figure 3C, hSlu7 associates as efficiently with the mutant spliceosome /designated the $\mathrm{C}_{\mathrm{GG}}$ complex) as with the wild type (cf. Figs. $3 \mathrm{C}$ and $2 \mathrm{~B}$ ). This result indicates that recognition of the AG dinucleotide for step II is not required for the association of hSlu7 with the spliceosome.

The pyrimidine tract is required for both catalytic steps of the splicing reaction (Reed 1989; Smith et al. 1989|. The step II role for the pyrimidine tract can be analyzed by use of the pre-mRNAs designated pyJ and RanA in Figure 3A (Chiara et al. 1997). The presence of pyrimidines downstream of the BPS in both pre-mRNAs allows efficient step I (Fig. 3D, 30-min time points). Step II, however, occurs only in the presence of additional pyrimidines (pyJ) but not when random sequence (RanA) is adjacent to the $3^{\prime}$ splice site AG [Fig. 3D, 60 min time point; the band labeled with an asterisk is most likely a breakdown product (see legend)]. Significantly, hSlu7 associates equally well with spliceosomes on both mutant pre-mRNAs (Fig. 3E). Thus, recognition of a pyrimidine tract adjacent to the AG is required for catalytic step II, but not for the association of hSlu7. Together, our results demonstrate that, as in yeast (Brys and Schwer 1996), 3' splice-site sequence elements are dispensable for the association of hSlu7 with the spliceosome.

\section{hSlu7 is a general step II splicing factor}

To investigate the function of hSlu7 in splicing, we immunodepleted hSlu7 from HeLa cell nuclear extracts. As shown in Figure 4A, hSlu7 is efficiently, though not completely, depleted. A control protein, the U2 snRNP component SAP 130, is present in equal amounts in $\Delta$ hSlu7 and mock-depleted extracts (Fig. 4A). These extracts were used to splice AdML pre-mRNA. Significantly, step II is inhibited, and the products of step I accumulate only in the $\Delta$ hSlu 7 extracts (Fig. 4B, 45-min time point). This inhibition is specific to step II, because the first step is not inhibited in $\Delta$ hSlu7 extracts (Fig. 4B, cf. mock and $\Delta$ hSlu7, 25-min time point). Step II is also inhibited in $\Delta$ hSlu 7 extracts when Ftz and $\beta$-globin pre- 
Figure 3. hSlu7 joins the spliceosome prior to recognition of the 3' splice site for catalytic step II. (A) Schematic of wildtype AdML (WT) and derivative premRNA substrates. The GG substrate contains an AG $\rightarrow$ GG substitution at the $3^{\prime}$ splice site, and the pyJ and RanA substrates contain insertions of pyrimidines (pyJ) and of random sequence (RanA) upstream of the AG. (BPS) Branchpoint sequence; (AG) wild-type AG dinucleotide at ${ }^{\prime}$ ' splice site; (GG) GG substitution at 3 ' splice site; py (20), a 20-nucleotide pyrimidine stretch; py (29), insertion of 29
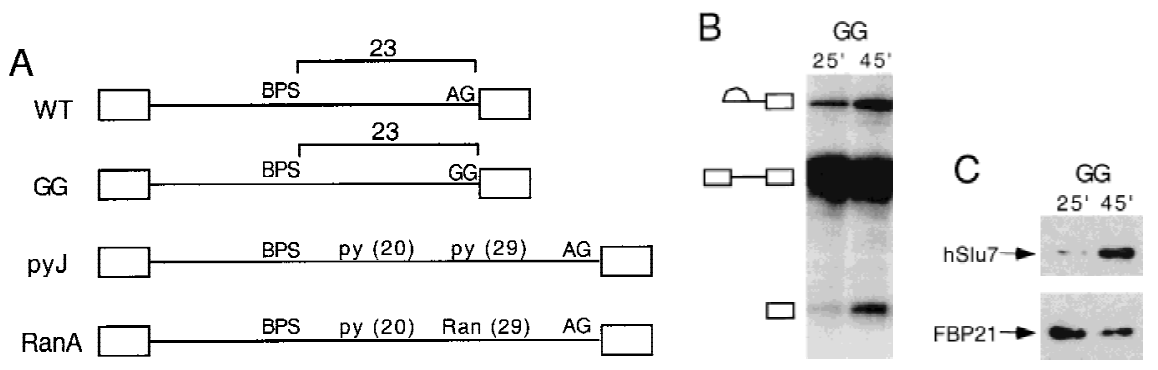
pyrimidines; Ran (29), insertion of 29 random nucleotides. $(B, D)$ RNA isolated from aliquots of large-scale splicing reactions performed with GG pre-mRNA $(B)$ or pyJ and RanA pre-mRNAs $(D)$. Incubations were carried out for the indicated times, and the spliceosomes were purified. The band marked by an asterisk is most likely a breakdown product of the lariat-exon 2 intermediate and not an excised intron resulting from use of a cryptic 3' splice site, because there is no band that could correspond to an accompanying mRNA. The band migrating just below the pre-mRNA in all four lanes cannot represent use of a cryptic 3' splice site because its levels decrease over time. $(C, E)$ Western blots of total protein from affinity-purified spliceosomal complexes formed in $B$ and $D$, respectively, probed with antibodies to hSlu7. Note that in $B$, the control protein FBP21 has been shown to associate with the spliceosome early, and then dissociates at late time points (M.T. Bedford, R. Reed, and P. Leder, unpubl.).
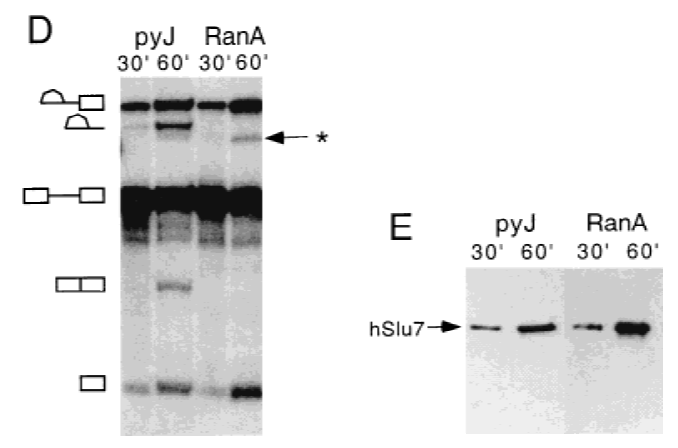

mRNAs are used as substrates (Fig. 4C,D). Note that the low levels of spliced products detected in $\Delta \mathrm{hSlu} 7 \mathrm{ex}-$ tracts may be due to residual hSlu7 remaining after depletion (see Fig. 4A).

To determine whether recombinant hSlu7 can reconstitute the depleted activity, we expressed hSlu7 in insect cells (Fig. 5A). Addition of the recombinant protein (rhSlu7) to depleted extract restores step II activity with all three pre-mRNA substrates (Fig. 5B-D). However, we note that step II is less efficient than in mock-depleted extracts (see Fig. 4B). This may be due to loss of activity of rhSlu7 during isolation and renaturation (see Materials and Methods). As expected, recombinant hPrp16 (rhPrp16), which efficiently complements hPrp16-depleted extracts (Zhou and Reed 1998), cannot overcome the step-II block in $\Delta$ hSlu7 extracts (Fig. 5B-D). Together, our observations demonstrate that hSlu7 is a general step II splicing factor.

\section{A novel spliceosomal complex accumulates in the absence of hSlut}

One approach to investigate the mechanism of spliceosomal remodeling between steps I and II is to isolate intermediates in this process. As depletion of hSlu 7 from splicing extracts inhibits step II, we asked whether a spliceosomal intermediate accumulates in $\Delta \mathrm{hSlu} 7$ extracts. First, we compared spliceosome assembly in $\Delta$ hSlu7 and mock-depleted extracts by native gel analysis (Fig. 6A). In mock-depleted extracts, the A complex is detected at 10 min, a mixture of $\mathrm{A}$ and $\mathrm{B}$ complexes is detected at 20 $\mathrm{min}$, and the $\mathrm{C}$ complex is detected at $45 \mathrm{~min}$. Strikingly, in $\Delta$ hSlu7 extracts, the wild-type C complex is not detected, and a novel spliceosomal complex migrating be-
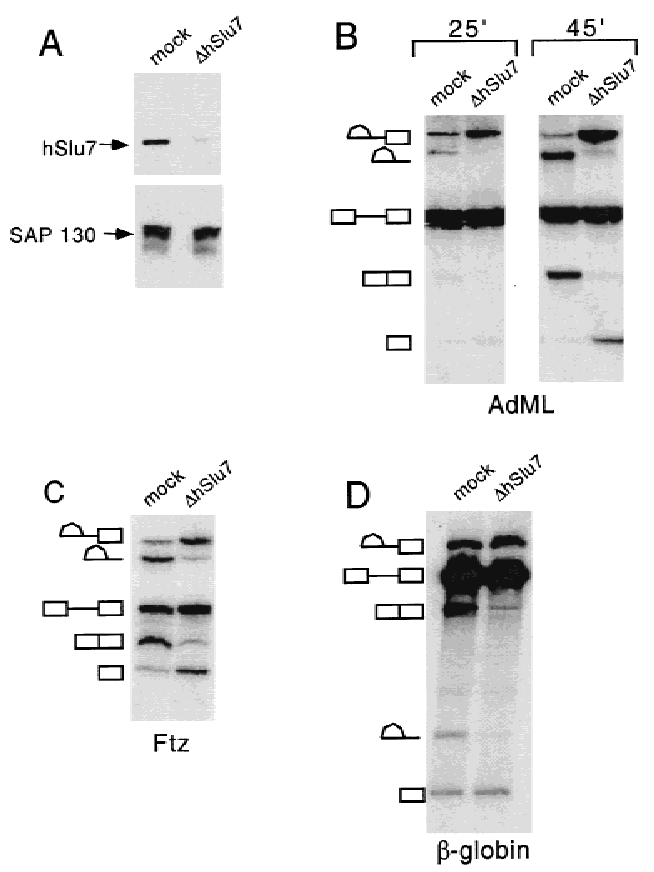

Figure 4. Splicing in $\Delta \mathrm{hSlu} 7$ extracts is blocked between the two catalytic steps. (A) Western blots of $\Delta \mathrm{hSlu} 7$ and mock-treated extracts probed with antibodies to hSlu7. The bands corresponding to hSlu7 and a control protein, SAP 130 , are indicated. $(B-D)$ Splicing in $\Delta \mathrm{hSlu} 7$ and mocktreated nuclear extracts with pre-mRNA substrates AdML $(B)$, Ftz $(C)$, and $\beta$-globin $(D)$. Uniformly labeled pre-mRNA was incubated under splicing conditions with $\Delta$ hSlu7 or mocktreated nuclear extracts for $60 \mathrm{~min}$, and total RNA was fractionated on a $15 \%(B, C)$ or $8 \%(D)$ denaturing polyacrylamide gel. Splicing intermediates and products are indicated. 


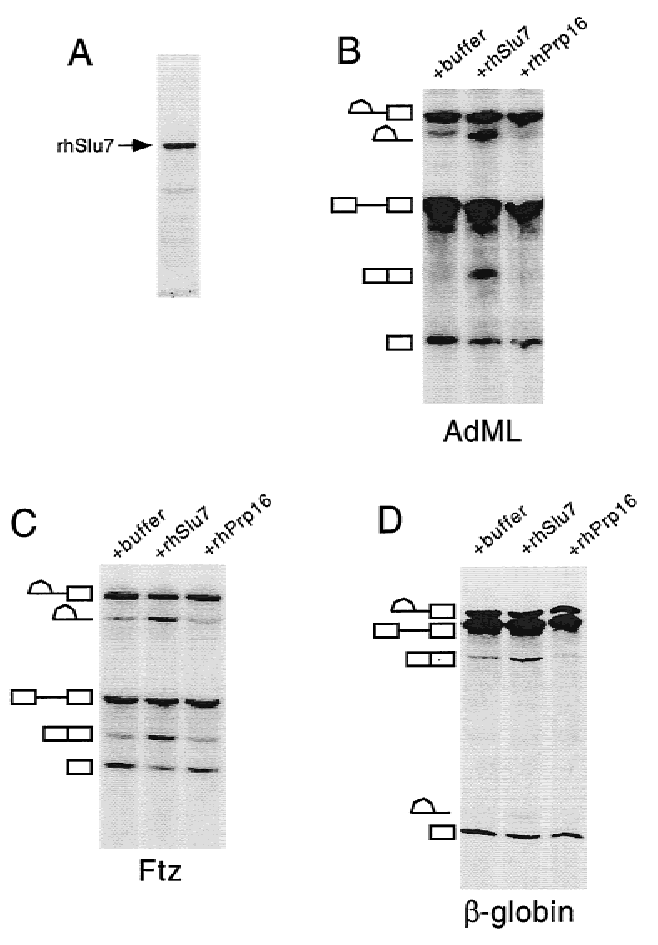

Figure 5. Recombinant hSlu7 reconstitutes step II activity to $\Delta$ hSlu7 extracts. (A) Recombinant hSlu7 (rhSlu7) expressed in Sf9 cells. $(B-D)$ Reconstitution of step II activity with rhSlu7 on $\operatorname{AdML}(B), \mathrm{Ftz}(C)$, and $\beta$-globin $(D)$ pre-mRNAs. $\Delta$ hSlu 7 extracts were used to splice the indicated pre-mRNAs in the presence of rhSlu7, rhPrp16, or buffer control. Splicing reactions were carried out for $60 \mathrm{~min}$, and total RNA fractionated on a $15 \%(B)$, $13.5 \%(C)$, or $8 \%(D)$ denaturing polyacrylamide gel.

tween the $\mathrm{A}$ and $\mathrm{B}$ complexes is detected at 45 (Fig. 6A) and $60 \mathrm{~min}$ (Fig. 8A, below). We have designated this novel complex the $\mathrm{C}_{\Delta \mathrm{hSlu}}$ complex. Analysis of the splicing intermediates and products in these reactions demonstrates that $\Delta$ hSlu7 and mock-depleted extracts differ only in step II (Fig. 6B). In addition, accumulation of the $\mathrm{C}_{\mathrm{AhSlu}}$ complex correlates with the accumulation of splicing intermediates (Fig. 6A,B).

To test directly whether the $\mathrm{C}_{\Delta \mathrm{hSlu}}$ complex contains the products of catalytic step I, the native gel lane containing this complex (shown horizontally in Fig. 6C) was excised from the gel, cut into five fragments, and the RNA species isolated from each fragment (Fig. 6C). Splicing complexes formed in mock-depleted extracts (7.5and 45-min incubations) are shown for comparison. As expected, pre-mRNA is detected in the A complex at the 7.5-min time point, and the lariat-exon 2 intermediate is detected in the $\mathrm{C}$ complex assembled on wild-type premRNA at the 45-min time point. Significantly, the lariat-exon 2 intermediate is also detected in the $\mathrm{C}_{\Delta \mathrm{hSlu}}$ complex, but not elsewhere in the native gel lane. Together, these observations identify the $\mathrm{C}_{\Delta \mathrm{hSlu}}$ complex as a novel complex blocked between the two catalytic steps.

Both mutation of the $3^{\prime}$ splice-site AG dinucleotide to GG and depletion of hSlu7 from splicing extracts result in accumulation of spliceosomal complexes blocked before catalytic step II (Fig. 6; Gozani et al. 1994). The observation that hSlu7 is present in the $\mathrm{C}_{\mathrm{GG}}$ complex (Fig. 3B and C) suggests that the $\mathrm{C}_{\Delta \mathrm{ASlu}}$ complex is a precursor to the $\mathrm{C}_{\mathrm{GG}}$ complex. To test this possibility, we incubated GG pre-mRNA in $\triangle \mathrm{hSlu} 7$ or mock-depleted extracts (Fig. 7A). As expected, the $\mathrm{C}_{\mathrm{GG}}$ complex, which comigrates with the wild-type C complex (Gozani et al. 1994), accumulates in mock-depleted extracts (Fig. 7B). In contrast, in $\Delta \mathrm{hSlu} 7$ extracts, the $\mathrm{C}_{\Delta \mathrm{hSlu}} \mathrm{c}$ complex accumulates, indicating that the $\mathrm{C}_{\Delta \mathrm{hSlu}}$ complex is blocked prior to formation of the $\mathrm{C}_{\mathrm{GG}}$ complex (Fig. 7B). Significantly, addition of rhSlu7 but not rhPrp16 allows formation of the $\mathrm{C}_{\mathrm{GG}}$ complex (Fig. 7C). Thus, accumulation of the $\mathrm{C}_{\Delta \mathrm{hSlu}}$ complex is due specifically to absence of the hSlu7 protein, and not to codepletion of an additional factor or to an irreversible side reaction occurring in the $\Delta$ hSlu7 extracts.
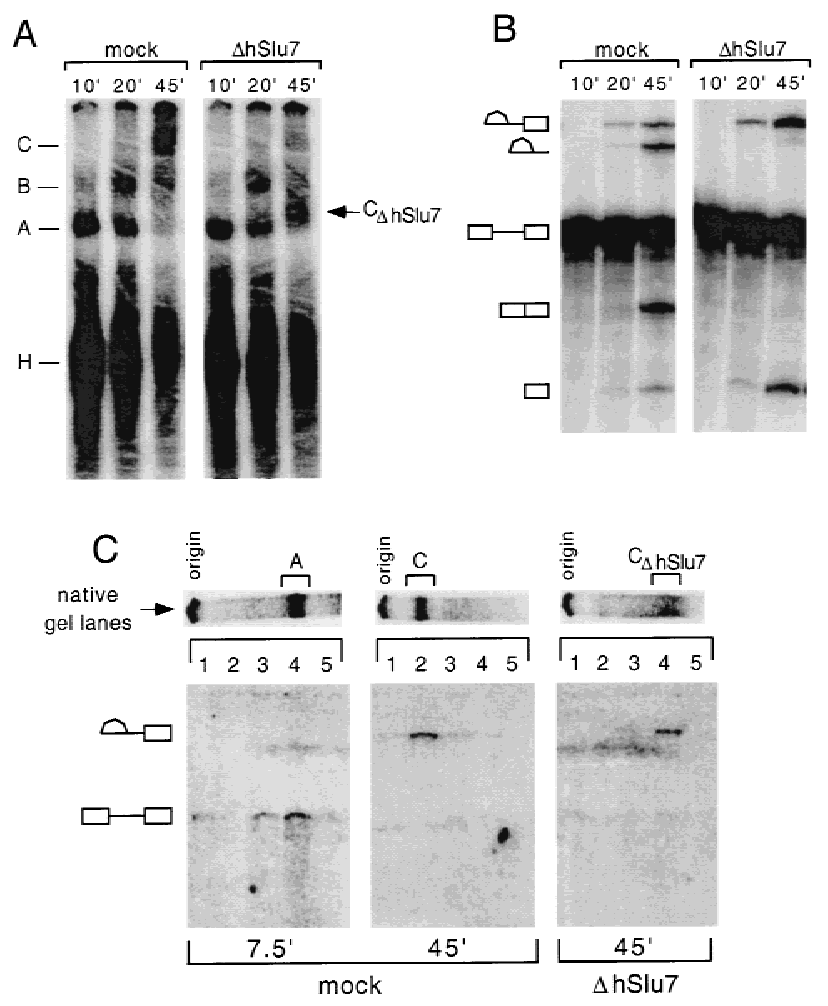

Figure 6. The $\mathrm{C}_{\Delta \mathrm{hSlu}}$ complex accumulates between the catalytic steps. (A) Spliceosome assembly in mock and $\Delta$ hSlu7 extracts. Wild-type AdML pre-mRNA was incubated under standard splicing conditions for the indicated times in mock-treated or $\Delta \mathrm{hSlu} 7$ extracts, and spliceosomal complexes detected by nondenaturing gel electrophoresis. (B) RNA isolated from aliquots of the splicing reactions used for native gels in $A$. $(C)$ RNA isolated from spliceosomal complexes shown in $A$. Native gels were transferred to Whatman paper and spliceosomal complexes detected by PhosphorImager analysis. Lanes containing the indicated complexes were excised and cut into five fragments (lanes 1-5). RNA was extracted from each fragment and run on a $15 \%$ denaturing polyacrylamide gel. The lanes containing the complexes are shown horizontally above the RNA gel. 
Figure 7. The $\mathrm{C}_{\Delta \mathrm{hSlu}}$ complex is a precursor to the $\mathrm{C}_{\mathrm{GG}}$ complex. (A) Splicing of GG pre-mRNA in mock or $\Delta \mathrm{hSlu} 7$ extracts. GG pre-mRNA was incubated under standard splicing conditions for the indicated times in mock-treated or $\Delta \mathrm{hSlu} 7$ extracts, and RNA was isolated and fractionated on a $15 \%$ denaturing polyacrylamide gel. $(B)$ Spliceosomal complex formation in splicing reactions shown in $A$, detected by non-denaturing gel electrophoresis. (C) Reconstitution of the $\mathrm{C}_{\mathrm{GG}}$ complex with rhSlu7. rhSlu7 or rhPrp16 (100 ng) was added to $\Delta$ hSlu7 extracts to splice GG pre-mRNA, and spliceosomal complexes were analyzed by native gels after 45-min incubations.
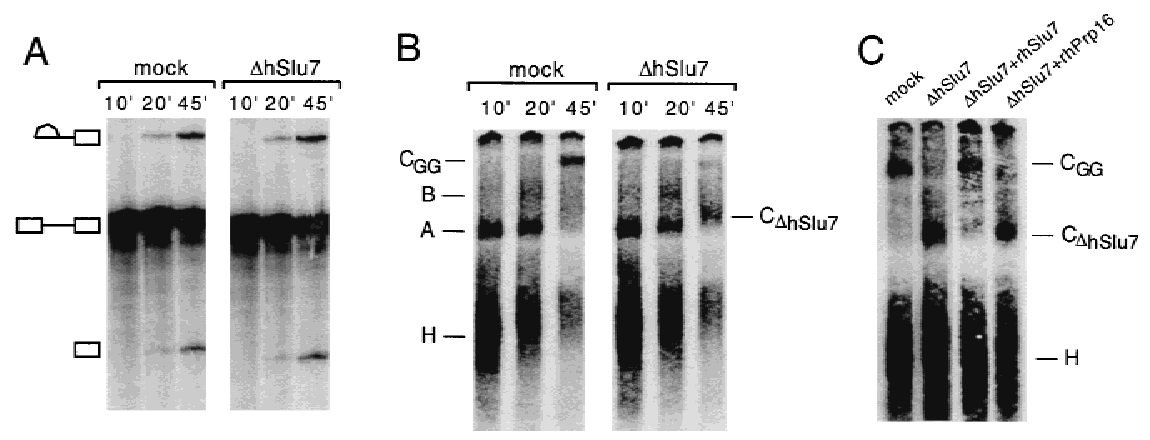

Evidence that the $C_{\Delta h S l u}$ complex is a functional intermediate

To determine the relationship between the $\mathrm{C}_{\Delta \mathrm{hSlu}}$ complex and the $\mathrm{C}_{\mathrm{II}}$ complex, we asked whether the $\mathrm{C}_{\Delta \mathrm{hSlu}}$ complex can be chased into the $\mathrm{C}_{\mathrm{II}}$ complex with recombinant rhSlu7 (Fig. 8A). The $\mathrm{C}_{\Delta \mathrm{hSlu}}$ complex was preformed by incubation of wild-type pre-mRNA in $\Delta \mathrm{hSlu} 7$ extracts for $60 \mathrm{~min}$ (Fig. 8A, lane 2). Then, recombinant rhSlu7 or rhPrp16 was added and complex formation analyzed after brief incubations. Significantly, with rhSlu7 but not rhPrp16, the $\mathrm{C}_{\Delta \mathrm{hSlu}}$ complex is converted into a band comigrating with the wild-type $\mathrm{C}_{\mathrm{II}}$ complex after as little as $5 \mathrm{~min}$ (data not shown), and $>50 \%$ of the $\mathrm{C}_{\Delta \mathrm{hSlu}}$ complex is driven into this $\mathrm{C}$ complex by $12 \mathrm{~min}$ (Fig. 8A, cf. lanes 1-4). The $\mathrm{C}_{\mathrm{II}}$ complex formed in the presence of rhSlu7 does not result from de novo complex formation because no C complex is detected even after a 20-min incubation in normal or mock-depleted extracts (see Fig. 6A, mock). These data indicate that rhSlu7 is necessary to convert the $\mathrm{C}_{\Delta \mathrm{hSlu}}$ complex into the $\mathrm{C}_{\mathrm{II}}$ complex, but do not address whether it is sufficient. Specifically, because the chase is performed in $\Delta \mathrm{hSlu} 7 \mathrm{ex}$ tracts, it is possible that additional factors present in the extract are also required during this transition.

To address this possibility, $\mathrm{C}_{\Delta \mathrm{hSlu}} \mathrm{c}$ complexes were preformed in large-scale reactions for $60 \mathrm{~min}$ and then fractionated by gel filtration. This procedure separates spliceosomal complexes from the nonspecific hnRNP complex H, as well as free proteins (Bennett et al. 1992). The $\mathrm{C}_{\Delta \mathrm{hSlu}}$ complex was present in a single gel filtration peak (data not shown) in the size range expected for spliceosomal complexes (Bennett et al. 1992; Gozani et al. 1994). To determine whether rhSlu7 is sufficient to convert the isolated $\mathrm{C}_{\Delta \mathrm{hSlu}}$ complex to the step II-competent spliceosome, an aliquot of the peak fraction was incubated with rhSlu7 or buffer control for $15 \mathrm{~min}$ in the presence of ATP (Fig. 8B, lanes 1,2). Notably, conversion of splicing intermediates to spliced products is not observed in the presence of rhSlu7 alone (Fig. 8B, lane 2). In contrast, spliced products are detected on incubation in a cytoplasmic S100 extract, which lacks SR proteins but contains all other essential splicing factors (Fig. 8B, cf. lanes 3 and 4; Krainer and Maniatis 1985; Ge et al. 1991; Krainer et al. 1991; Zahler et al. 1992, 1993). The splicing intermediates accumulated for $60 \mathrm{~min}$ in the $\mathrm{C}_{\Delta \mathrm{hSlu}}$ complex could also be chased to spliced products after a 10-min incubation in normal splicing extracts (data not shown). In both S100 and normal extracts, it is unlikely that the spliced products derive from de novo splicing of pre-mRNA, as they are not normally detected after 15 min of incubation (see Fig. 2A). It is also unlikely that the spliced products are derived from $\mathrm{A}$ and $\mathrm{B}$ complexes, because these complexes are not detected in the 60-min $\Delta$ hSlu7 reactions used for the chase (see Fig. 8A, lane 2). Thus, our data indicate that the $\mathrm{C}_{\Delta \mathrm{hSlu}}$ complex is a functional splicing intermediate, but is deficient in at least one step II activity in addition to hSlu7. This ac-
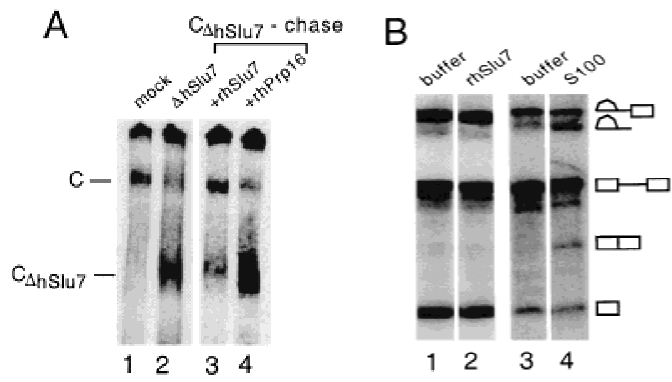

Figure 8. The $\mathrm{C}_{\Delta \mathrm{hSlu}}$ complex is a functional precursor to the wild-type $\mathrm{C}_{\mathrm{II}}$ complex. (A) Chase of pre-formed $\mathrm{C}_{\Delta \mathrm{hSlu}}$ complexes into the $\mathrm{C}_{\mathrm{II}}$ complex with recombinant hSlu7. $\mathrm{C}_{\Delta \mathrm{hSlu}} \mathrm{7}$ complexes were preformed for $60 \mathrm{~min}$ in $\Delta \mathrm{hSlu} 7$ extract (lane 2), and incubated for $12 \mathrm{~min}$ in the presence of rhslu7 (lane 3) or rhPrp16 (lane 4). A 60-min incubation in mock-treated extract is shown for comparison (lane 1). (B) Chase of isolated $\mathrm{C}_{\Delta \mathrm{hSlu}}$ complexes to complete splicing. $\mathrm{C}_{\Delta \mathrm{hSlu}}$ complexes were preformed in $\Delta \mathrm{hSlu} 7$ extract, and separated from free splicing factors by gel filtration. Aliquots from the peak fraction were chased for $15 \mathrm{~min}$ under splicing conditions with buffer control (lanes 1,3), rhSlu7 (lane 2), or S100 extract (lane 4). Splicing intermediates and products are indicated. We note that the mRNA appears to be preferentially degraded in the S100 extract, most likely due to high levels of nuclease present in the extract (Abmayr et al. 1988). 
tivity is due to a factor (or factors) that is present in both S100 and $\Delta$ hSlu7 extracts (Figs. $7 \mathrm{C}$ and $8 \mathrm{~A}$ ) but that is not stably associated with the $\mathrm{C}_{\Delta \mathrm{hslu}}$ complex. Together, these studies identify the $\mathrm{C}_{\Delta \mathrm{hSlu}}$ complex as a novel precursor to the catalytically active $\mathrm{C}_{\text {II }}$ complex and a functional intermediate in the splicing pathway.

\section{Discussion}

During the first catalytic step of splicing, pre-mRNA is cleaved immediately upstream of the GU at the 5' splice site. Prior to this reaction, numerous RNA-RNA, RNAprotein, and protein-protein interactions take place as the spliceosome assembles on pre-mRNA in a step-wise pathway (for reviews, see Moore et al. 1993; Reed and Palandjian 1997; Will 1997). These interactions are not only critical for establishing the active site for step I, but are also fundamental to the mechanism for achieving the high levels of fidelity required for catalysis (Madhani and Guthrie 1994; Nilsen 1994). The spliceosome undergoes extensive remodeling between steps I and II (for reviews, see Nilsen 1994; Umen and Guthrie 1995c; Staley and Guthrie 1998). It is likely that a similarly complex network of interactions is involved in this remodeling process and is necessary for achieving fidelity for catalytic step II. Therefore, the identification and characterization of proteins that function between steps I and II provide insights into the nature of the remodeling. In yeast, four splicing factors, Slu7 and Prp16, Prp17, and Prp18, are required specifically for step II (for review, see Umen and Guthrie 1995c), and in metazoans, the counterparts of three of these proteins (hPrp16, hPrp17, and hPrp18) have been identified (Horowitz and Krainer 1997; Ben Yehuda et al. 1998; Lindsey and Garcia-Blanco 1998; Zhou and Reed 1998). Here, we report the isolation of the human homolog of Slu7 and show that it too is required exclusively for step II. We provide evidence that this protein associates with the spliceosome after catalysis of step I and may trigger an essential step in the establishment of the catalytically active spliceosome for step II.

\section{A novel spliceosomal intermediate between the catalytic steps}

Four spliceosomal complexes, which assemble in the or$\operatorname{der} \mathrm{E}, \mathrm{A}, \mathrm{B}$, and $\mathrm{C}$, have been well characterized as discrete functional intermediates in the splicing pathway (for reviews, see Moore et al. 1993; Reed and Palandjian 1997). Although the C complex appears as a single discrete band on native gels, considerable evidence indicates that significant rearrangements take place between the two catalytic steps and that these reactions are catalyzed by distinct configurations of the C complex (for reviews, see Moore et al. 1993; Staley and Guthrie 1998). Minimally, during conversion of the $\mathrm{C}_{\mathrm{I}}$ to the $\mathrm{C}_{\mathrm{II}}$ complex, the chemical groups involved in the step I transesterification must be displaced from the active site, which then must be reconfigured around the reactive groups for the step II reaction. Despite the extensive remodeling that takes place between steps I and II, distinct complexes corresponding to the $\mathrm{C}_{\mathrm{I}}$ and $\mathrm{C}_{\mathrm{II}}$ complexes or intermediate stages in this process have not been distinguished by native gel analysis.

In this study, we have identified such an intermediate, a novel complex that accumulates in extracts specifically depleted of hSlu7. This complex, the $\mathrm{C}_{\Delta \mathrm{hSlu}}$ complex, together with other previously identified step II events, can be used to define distinct stages in the transition from step I to step II. We demonstrate that the $\mathrm{C}_{\Delta \mathrm{hSlu}}$ complex is blocked at a stage preceding a structural alteration of the spliceosome for which hSlu7 is required. Specifically, we observe a dramatic difference in mobility between the $\mathrm{C}_{\Delta \mathrm{hSlu}} \mathrm{c}$ complex and the wildtype $\mathrm{C}$ complex on a native gel. Significantly, the $\mathrm{C}_{\Delta \mathrm{hslu}}$ complex can be chased to a complex that comigrates with the wild-type $\mathrm{C}_{\mathrm{II}}$ complex, and this conversion is observed as a large shift in the spliceosome's electrophoretic mobility. These data indicate that the $\mathrm{C}_{\Delta \mathrm{hSlu}} \mathrm{com}$ plex is a functional spliceosomal intermediate between steps I and II that is biochemically distinct from the wild-type C complex. Our identification of the $\mathrm{C}_{\Delta \mathrm{hslu}}$ complex highlights the fact that the kinetics of the rearrangements between the catalytic steps of splicing are extremely fast, and specific stages in this process can be discerned only when a transition is made rate limiting by depletion of an essential step II factor.

The large mobility shift detected on native gels during conversion of the $\mathrm{C}_{\Delta \mathrm{hSlu}}$ complex to the wild-type $\mathrm{C}_{\mathrm{II}}$ complex may reflect alterations in the spliceosome's composition, stability, or structure. The nature of this alteration is likely to be complex, as the dramatic shift in electrophoretic mobility cannot be accounted for by the size of the hSlu7 protein alone. Indeed, our observations indicate that conversion of the $\mathrm{C}_{\Delta \mathrm{hSlu}}$ complex to the catalytically active step II spliceosome requires at least one additional step II splicing activity other than hSlu 7 itself. This activity is present in cytoplasmic S100 and $\Delta$ hSlu7 extracts, but does not co-fractionate with the $\mathrm{C}_{\Delta \mathrm{hSlu}}$ complex by gel filtration. The missing activity may be due to one or more factors, which function concomitant with or subsequent to hSlu7, or are required to activate hSlu7. These factors are likely to include hPrp18, because this protein (and its yeast homolog Prp18) is thought to function at a very late stage between catalytic steps I and II and is only transiently associated with the spliceosome (Horowitz and Krainer 1997). One possibility is that hSlu7 is required for the stability of one or more spliceosome components. We note, however, that we have been unable to detect a difference in the snRNP composition of the $\mathrm{C}_{\Delta \mathrm{hSlu}}$ complex and that of the wild-type C complex (K. Chua and R. Reed, unpubl.). Our data are consistent with observations in $S$. cerevisiae, in which a $\Delta$ Slu 7 spliceosome was purified by gradient sedimentation. Like the $\mathrm{C}_{\Delta \mathrm{hSlu}}$ complex, this spliceosome is a functional splicing intermediate, but conversion to the catalytically active step II spliceosome requires factors in addition to Slu7 (Ansari and Schwer 1995).

In the absence of hSlu7, the products of catalytic step 
I accumulate in the $\mathrm{C}_{\Delta \mathrm{hSlu}}$ complex. It is possible that the $\mathrm{C}_{\Delta \mathrm{hSlu}}$ complex corresponds to the configuration of the spliceosome immediately following catalysis of step $\mathrm{I}$, and may thus be similar or identical in structure to the $\mathrm{C}_{\mathrm{I}}$ complex. However, functional ordering of step II splicing factors in yeast has indicated that at least two proteins, Prp16 and Prp17, function after step I but before Slu7 (Ansari and Schwer 1995; Jones et al. 1995), and preliminary studies suggest that the human orthologs of these proteins function in the same order (Z. Zhou and R. Reed, unpubl.). These observations suggest that the $\mathrm{C}_{\Delta \mathrm{hSlu} 7}$ complex is distinct from the $\mathrm{C}_{\mathrm{I}}$ complex.

We have also demonstrated that the $\mathrm{C}_{\Delta \mathrm{hSlu} 7}$ complex is blocked at a stage preceding formation of the $\mathrm{C}_{\mathrm{GG}}$ complex (see Fig. 7C), which accumulates on a premRNA containing an AG $\rightarrow$ GG mutation at the $3^{\prime}$ splice site and is arrested between catalytic steps I and II (Gozani et al. 1994). Although the $\mathrm{C}_{\mathrm{GG}}$ complex is a dead end complex, characterization of its snRNA and protein composition suggested that the $\mathrm{C}_{\mathrm{GG}}$ complex might represent the same spliceosomal configuration as the $\mathrm{C}_{\mathrm{II}}$ complex assembled on wild-type pre-mRNAs (Gozani et al. 1994). At least one observation, however, indicates the $\mathrm{C}_{\mathrm{GG}}$ complex is distinct from the wild-type $\mathrm{C}_{\mathrm{II}}$ complex. Specifically, the crosslinking of an $\sim 75 \mathrm{kD}$ protein [designated $\mathrm{AG}^{75}$ (Chiara et al. 1996) and p70 (Wu and Green 1997)] to the RNA at the AG dinucleotide is detected in the wild-type $\mathrm{C}$ complex but not in the $\mathrm{C}_{\mathrm{GG}}$ complex. However, the $\mathrm{C}_{\mathrm{GG}}$ complex comigrates on native gels with the wild-type C complex (this study; Gozani et al. 1994), rather than with the $\mathrm{C}_{\Delta \mathrm{hslu}}$ complex. Thus, an AG dinucleotide at the $3^{\prime}$ splice site is not required for the decrease in mobility observed on native gels on addition of rhSlu7 to the $\mathrm{C}_{\Delta \mathrm{hSlu}} \mathrm{c}$ complex.

Similarly, the AG dinucleotide is not required for a number of events that have been implicated previously in remodeling the spliceosome for step II, and these events may contribute to the large mobility shift detected on native gels between the $\mathrm{C}_{\Delta \mathrm{hSlu} 7}$ and $\mathrm{C}_{\mathrm{GG}}$ complexes. Fourteen spliceosome-associated proteins (SAPs) become stably associated with the spliceosome between the $\mathrm{B}$ and $\mathrm{C}$ complexes and are present in the $\mathrm{C}_{\mathrm{GG}}$ complex (Gozani et al. 1994). Modification and repositioning of splicing factors that have roles in earlier stages of the splicing pathway are also detected in the $\mathrm{C}_{\mathrm{GG}}$ complex. Specifically, the U2 snRNP protein SAP 155 becomes hyperphosphorylated (Wang et al. 1998), and the U5 snRNP proteins $\mathrm{U} 5^{110}, \mathrm{U} 5^{116}$, and $\mathrm{U} 5^{220}$ are repositioned to contact the pyrimidine tract at the $3^{\prime}$ splice site, where they can be UV cross-linked to the RNA /Chiara et al. 1997). Future studies may allow more precise delineation of the timing of these events.

A pyrimidine tract located immediately adjacent to the AG dinucleotide at the 3 ' splice site is essential for step II and may function to specify the AG that serves as the site of exon ligation (Chiara et al. 1997). It has been proposed that the repositioning of U5 snRNP on the 3' splice site may underlie this sequence requirement (Chiara et al. 1997), and consistent with this model, antibodies to the U5 snRNP proteins U5 ${ }^{116}$ (Fabrizio et al. 1997) and U5 ${ }^{200}$ (Lauber et al. 1996) can inhibit step II. As hSlu7, hPrp16, and hPrp17 are all stably associated with the spliceosome in the absence of such a pyrimidine tract (see Fig. 3; Zhou and Reed 1998), recognition of the pyrimidine tract for step II most likely occurs in a stage following the association of these proteins. Indeed, one possibility is that the conversion of the $\mathrm{C}_{\Delta \mathrm{hSlu}}$ complex to the catalytically active $\mathrm{C}_{\mathrm{II}}$ complex may involve the incorporation of the pyrimidine tract at the $3^{\prime}$ splice site into the catalytic center of the spliceosome.

This model fits well with studies of the step II splicing factors in S. cerevisiae. Specifically, the association of Slu7 with the spliceosome in $S$. cerevisiae occurs even when 3 ' splice site sequences are removed by RNase digestion, suggesting that at least the initial association of Slu7 precedes incorporation of the 3 ' splice site (Brys and Schwer 1996). However, Slu 7 is thought to be positioned at or near the 3' splice site at a time very close to catalysis of step II, because it (as well as Prp8) can be UV cross-linked to a 15-nucleotide RNase digestion product containing the 3' splice site (Umen and Guthrie 1995b). Moreover, a differential step II requirement for Slu 7 has been described, depending on the location of the 3 ' splice site, suggesting that Slu7 may initiate the recruitment of distant 3' splice sites (Brys and Schwer 1996; Frank and Guthrie 1992). Therefore, it has been proposed that Slu7 first associates with the spliceosome (possibly via protein-protein interactions) independent of the $3^{\prime}$ splice site and is subsequently repositioned along with $\operatorname{Prp} 8$ onto the 3 ' splice site (Brys and Schwer 1996). Thus, both the $\mathrm{C}_{\Delta \mathrm{hSlu}}$ complex in humans and the $\Delta$ Slu 7 complex in yeast may represent stages in the transition between steps I and II, in which the spliceosome has not yet reconfigured itself around the 3 ' splice site.

\section{Materials and methods}

Plasmids

Wild-type AdML pre-mRNA is encoded by pAdML described in (Michaud and Reed 1993). GG (previously designated GG-GG), PyJ, and RanA pre-mRNAs are derived from pAdML (Chiara et al. 1997). All AdML derivatives were linearized with BamHI and transcribed with T7 RNA polymerase. Ftz pre-mRNA (Rio 1988) was linearized with XhoI and transcribed with T7 RNA polymerase. $\alpha$-TM pre-mRNA (Smith and Nadal-Ginard 1989) was linearized with BamHI and transcribed with SP6 RNA polymerase.

\section{Isolation of hSlu7 cDNA}

The BLAST program was used to search the GenBank database for sequences that resemble the Slu7 protein sequence (Frank and Guthrie 1992). A C. elegans ORF (GenBank accession no. Z71181) was identified as the most similar to Slu7. A second database search for sequences resembling this C. elegans sequence identified several human EST sequences. One of these (GenBank accession no. AA076462) was used to design oligonucleotide primers (5'-GAGGCTGGACATGTTCATCTGGAGC-3' and 5'-TCTGGAGAATGGTACAAGAGGGG-3') for PCR. Overlapping $5^{\prime}$ and $3^{\prime}$ RACE products were amplified from HeLa cell cDNAs by use of the Marathon RACE kit (Clontech). 
On the basis of the sequences of these RACE products, a fulllength cDNA was then amplified by PCR and subcloned into the pCR2.1 vector (Invitrogen).

\section{Immunodepletion and reconstitution}

hSlu7 fragments encoding amino acids 15-157 and 15-172 were subcloned into pGEX-2TK (Pharmacia), and GST fusion proteins were expressed in E. coli. Recombinant protein was affinity purified with glutathione-Sepharose 4B (Pharmacia) and eluted with reduced glutathione. Rabbit polyclonal antibodies were raised against a mixture of these fusion proteins (Covance Research Products, Denver, PA). For immunodepletions, $60 \mu \mathrm{l}$ of hSlu7 or pre-immune antibodies were coupled to $250 \mu \mathrm{l}$ of protein A-Sepharose CL-4B (Pharmacia), and used to deplete four volumes of nuclear extract in $700 \mathrm{~mm} \mathrm{KCl}$. Three sequential depletions were carried out for $1 \mathrm{hr}$ each, rotating at $4^{\circ} \mathrm{C}$. The resulting extracts were dialyzed against $20 \mathrm{~mm}$ HEPES $/ \mathrm{pH}$ 7.9), $100 \mathrm{~mm} \mathrm{KCl}, 0.2 \mathrm{~mm}$ EDTA, 20\% glycerol, $0.2 \mathrm{~mm}$ PMSF, and $0.5 \mathrm{~mm}$ DTT. Recombinant hSlu7 and hPrp16 were expressed using the Bac-to-Bac baculovirus expression system (Gibco/BRL). Sf9 cells were infected with recombinant baculovirus, harvested after $48 \mathrm{hr}$, and lysed by sonication in $20 \mathrm{~mm}$ Tris- $\mathrm{HCl}$ (pH 8.5), $10 \mathrm{~mm}$ 2-mercapthoethanol, $1 \mathrm{~mm}$ PMSF, and $1 \%$ NP-40. Centrifugation of total cell lysate produced an inclusion body pellet highly enriched in recombinant protein. Further purification was accomplished by sequential washes in 2 and $4 \mathrm{~m}$ urea. The final pellet was solubilized in $6 \mathrm{M}$ urea, and the resulting protein renatured by dialysis into $20 \mathrm{mM}$ HEPES (pH 7.9), 100 mm KCl, 1 mM PMSF, 0.5 mm DTT. Recombinant protein (100 ng) was added to $\Delta \mathrm{hSlu} 7$ splicing reactions $(25 \mu \mathrm{l})$ to reconstitute splicing activity.

\section{Analysis of spliceosomal complexes}

Biotinylated, ${ }^{32} \mathrm{P}$-labeled pre-mRNA $(1.92 \mu \mathrm{g})$ was incubated in 2.4-ml splicing reactions. Spliceosomal complexes were isolated by gel filtration and affinity purification on avidin-agarose, and RNA or protein analyzed as described previously (Reed 1990; Bennett et al. 1992). For time-course experiments, equal amounts of purified complex were used for each time point. For Western analysis, proteins eluted from purified spliceosomal complexes assembled on 80-100 ng pre-mRNA were loaded in each lane.

\section{Native gel analysis}

${ }^{32} \mathrm{P}$-Labeled wild-type AdML or GG mutant pre-mRNA (20 ng) was incubated in $25-\mu 1$ splicing reactions for the indicated times. Three microliters of $6.5 \mathrm{mg} / \mathrm{ml}$ heparin $/ 50 \%$ ficoll dye was added and the samples incubated at room temperature for 5 min. Four microliters of the samples were run on $4 \%$ Trisglycine polyacrylamide gels (Konarska and Sharp 1987). Gels were transferred to Whatman paper, dried, and detected by PhosphorImager analysis. RNA was isolated from $20 \mu \mathrm{l}$ of the reactions and run on $15 \%$ denaturing gels to analyze splicing in each sample.

\section{Acknowledgments}

We thank R. Das and J. Kim for technical assistance, and O. Gozani, B. Graveley, K.J. Hertel, and Z. Zhou for critical comments. This work was supported by a National Institutes of Health grant to R.R.

The publication costs of this article were defrayed in part by payment of page charges. This article must therefore be hereby marked 'advertisement' in accordance with 18 USC section 1734 solely to indicate this fact.

\section{References}

Abmayr, S.M., R. Reed, and T. Maniatis. 1988. Identification of a functional mammalian spliceosome containing unspliced pre-mRNA. Proc. Nat1. Acad. Sci. 85: 7216-7220.

Abovich, N. and M. Rosbash. 1997. Cross-intron bridging interactions in the yeast commitment complex are conserved in mammals. Cell 89: 403-412.

Aebi, M., H. Hornig, R.A. Padgett, J. Reiser, and C. Weissmann. 1986. Sequence requirements for splicing of higher eukaryotic nuclear pre-mRNA. Cell 47: 555-565.

Ansari, A. and B. Schwer. 1995. SLU7 and a novel activity, SSF1, act during the PRP16-dependent step of yeast pre-mRNA splicing. EMBO J. 14: 4001-4009.

Arning, S., P. Gruter, G. Bilbe, and A. Kramer. 1996. Mammalian splicing factor SF1 is encoded by variant cDNAs and binds to RNA. RNA 2: 794-810.

Ben Yehuda, S., I. Dix, C.S. Russell, S. Levy, J.D. Beggs, and M. Kupiec. 1998. Identification and functional analysis of hPRP17, the human homologue of the PRP17/CDC40 yeast gene involved in splicing and cell cycle control. RNA 4: 1304-1312.

Bennett, M., S. Michaud, J. Kingston, and R. Reed. 1992. Protein components specifically associated with prespliceosome and spliceosome complexes. Genes \& Dev. 6: 1986-2000.

Brown, J.D. and J.D. Beggs. 1992. Roles of PRP8 protein in the assembly of splicing complexes. EMBO J. 11:3721-3729.

Brys, A. and B. Schwer. 1996. Requirement for SLU7 in yeast pre-mRNA splicing is dictated by the distance between the branchpoint and the $3^{\prime}$ splice site. RNA 2: 707-717.

Burgess, S., J.R. Couto, and C. Guthrie. 1990. A putative ATP binding protein influences the fidelity of branchpoint recognition in yeast splicing. Cell 60: 705-717.

Cavaloc, Y. M. Poplielarz, JP. Fuchs, R. Gattoni, and J. Stevenin. 1994. Characterization and cloning of the human splicing factor 9G8: A novel $35 \mathrm{kDa}$ factor of the serine/arginine protein family. EMBO J. 13: 2639-2649.

Cheng, S.C. and J. Abelson. 1987. Spliceosome assembly in yeast. Genes \& Dev. 1: 1014-1027.

Chiara, M., O. Gozani, M. Bennett, P. Champion-Arnaud, L. Palandjian, and R. Reed. 1996. Identification of proteins that interact with exon sequences, splice sites, and the branchpoint sequence during each stage of spliceosome assembly. Mol. Cell. Biol. 16: 3317-3326.

Chiara, M.D., L. Palandjian, R. Feld Kramer, and R. Reed. 1997. Evidence that U5 snRNP recognizes the 3' splice site for catalytic step II in mammals. EMBO J. 16: 4746-4759.

Couto, J.R., J. Tamm, R. Parker, and C. Guthrie. 1987. A transacting suppressor restores splicing of a yeast intron with a branch point mutation. Genes \& Dev. 1: 445-455.

Fabrizio, P., B. Laggerbauer, J. Lauber, W.S. Lane, and R. Luhrmann. 1997. An evolutionarily conserved U5 snRNP-specific protein is a GTP-binding factor closely related to the ribosomal translocase EF-2. EMBO J. 16: 4092-4106.

Frank, D. and C. Guthrie. 1992. An essential splicing factor, SLU7, mediates $3^{\prime}$ splice site choice in yeast. Genes \& Dev. 6: $2112-2124$.

Ge, H., P. Zuo, and J.L. Manley. 1991. Primary structure of the human splicing factor ASF reveals similarities with Drosophila regulators. Cell 66: 373-382.

Gozani, O., J.G. Patton, and R. Reed. 1994. A novel set of spli- 
ceosome-associated proteins and the essential splicing factor PSF bind stably to pre-mRNA prior to catalytic step II of the splicing reaction. EMBO I. 13: 3356-3367.

Horowitz, D.S. and J. Abelson. 1993. Stages in the second reaction of pre-mRNA splicing: The final step is ATP independent. Genes \& Dev. 7: 320-329.

- 1993. A U5 small nuclear ribonucleoprotein particle protein involved only in the second step of pre-mRNA splicing in Saccharomyces cerevisiae. Mol. Cell. Biol. 13: 29592970.

Horowitz, D.S. and A.R. Krainer. 1997. A human protein required for the second step of pre-mRNA splicing is functionally related to a yeast splicing factor. Genes \& Dev. 11: 139151.

Jones, M.H., D.N. Frank, and C. Guthrie. 1995. Characterization and functional ordering of Slu $7 \mathrm{p}$ and Prp $17 \mathrm{p}$ during the second step of pre-mRNA splicing in yeast. Proc. Natl. Acad. Sci. 92: 9687-9691.

Konarska, M.M. and P.A. Sharp. 1987. Interactions between small nuclear ribonucleoprotein particles in formation of spliceosomes. Cell 49: 763-774.

Krainer, A.R. and T. Maniatis. 1985. Multiple factors including the small nuclear ribonucleoproteins $\mathrm{U} 1$ and $\mathrm{U} 2$ are necessary for pre-mRNA splicing in vitro. Cell 42: 725-736.

Krainer, A.R., A. Mayeda, D. Kozak, and G. Binns. 1991. Functional expression of cloned human splicing factor SF2: Homology to RNA-binding proteins, U1 70K, and Drosophila splicing regulators. Cell 66: 383-394.

Kramer, A. 1996. The structure and function of proteins involved in mammalian pre-RNA splicing. Annu. Rev. Biochem. 65: 367-409.

Lamond, A.I., M.M. Konarska, P.J. Grabowski, and P.A. Sharp. 1988. Spliceosome assembly involves the binding and release of U4 small nuclear ribonucleoprotein. Proc. Natl. Acad. Sci. 85: 411-415.

Lauber, J., P. Fabrizio, S. Teigelkamp, W.S. Lane, E. Hartmann, and R. Luhrmann. 1996. The HeLa 200 kD U5 snRNP-specific protein and its homologue in Saccharomyces cerevisiae are members of the DEXH-box protein family of putative RNA helicases. EMBO I. 15: 4001-4015.

Lindsey, L.A. and M.A. Garcia-Blanco. 1998. Functional conservation of the human homolog of the yeast pre-mRNA splicing factor Prp17p. J. Biol. Chem. 273: 32771-32775.

Madhani, H.D. and C. Guthrie. 1994. Dynamic RNA-RNA interactions in the spliceosome. Annu. Rev. Genet. 28: 1-26.

Michaud, S. and R. Reed. 1993. A functional association between the $5^{\prime}$ and $3^{\prime}$ splice site is established in the earliest prespliceosome complex (E) in mammals. Genes \& Dev. 7: 1008-1020.

Moore, M.J., C.C. Query, and P.A. Sharp. 1993. Splicing of precursors to messenger RNAs by the spliceosome. In The RNA world (ed. R.F. Gesteland and J.F. Atkins), pp. 303-357. Cold Spring Harbor Laboratory Press, Cold Spring Harbor, NY.

Newman, A.J. and C. Norman. 1992. U5 snRNA interacts with exon sequences at $5^{\prime}$ and $3^{\prime}$ splice sites. Cell 68: 743-754.

Nilsen, T.W. 1994. RNA-RNA interactions in the spliceosome: Unraveling the ties that bind. Cell 78: 1-4.

Pikielny, C.W., B.C. Rymond, and M. Rosbash. 1986. Electrophoresis of ribonucleoproteins reveals an ordered assembly pathway of yeast splicing complexes. Nature 324: 341-345.

Reed, R. 1989. The organization of $3^{\prime}$ splice-site sequences in mammalian introns. Genes \& Dev. 3: 2113-2123.

- 1990. Protein composition of mammalian spliceosomes assembled in vitro. Proc. Natl. Acad. Sci. 87: 8031-8035.

Reed, R. and T. Maniatis. 1985. Intron sequences involved in lariat formation during pre-mRNA splicing. Cell 41: 95-105.
Reed, R. and L. Palandiian. 1997. Splicesome assembly. In Eukaryotic mRNA processing (ed. A.R. Krainer), pp. 103-129. Oxford University Press, Oxford, UK.

Rio, D.C. 1988. Accurate and efficient pre-mRNA splicing in Drosophila cell-free extracts. Proc. Natl. Acad. Sci. 85: 2904-2908.

Schwer, B. and C. Gross. 1998. Prp22, a DExH-box RNA helicase, plays two distinct roles in yeast pre-mRNA splicing. EMBO T. 17: 2086-2094.

Schwer, B. and C. Guthrie. 1991. PRP16 is an RNA-dependent ATPase that interacts transiently with the spliceosome. $\mathrm{Na}$ ture 349: 494-499.

- 1992. A conformational rearrangement in the spliceosome is dependent on PRP16 and ATP hydrolysis. EMBO J. 11: 5033-5039.

Smith, C.W. and B. Nadal-Ginard. 1989. Mutually exclusive splicing of alpha-tropomyosin exons enforced by an unusual lariat branch point location: Implications for constitutive splicing. Cell 56: 749-758.

Smith, C.W., E.B. Porro, J.G. Patton, and B. Nadal-Ginard. 1989. Scanning from an independently specified branch point defines the $3^{\prime}$ splice site of mammalian introns. Nature 342: 243-247.

Staley, J.P. and C. Guthrie. 1998. Mechanical devices of the spliceosome: Motors, clocks, springs, and things. Cell 92: 315-326.

Teigelkamp, S., A.J. Newman, and J.D. Beggs. 1995. Extensive interactions of PRP8 protein with the $5^{\prime}$ and $3^{\prime}$ splice sites during splicing suggest a role in stabilization of exon alignment by U5 snRNA. EMBO J. 14: 2602-2612.

Umen, J.G. and C. Guthrie. 1995a. A novel role for a U5 snRNP protein in 3' splice site selection. Genes \& Dev. 9: 855-868. . 1995b. Prp16p, Slu7p, and Prp8p interact with the 3' splice site in two distinct stages during the second catalytic step of pre-mRNA splicing. RNA 1: 584-597.

. 1995c. The second catalytic step of pre-mRNA splicing. RNA 1: 869-885.

Vijayraghavan, U. and J. Abelson. 1990. PRP18, a protein required for the second reaction in pre-mRNA splicing. Mol. Cell. Biol. 10: 324-332.

Vijayraghavan, U., M. Company, and J. Abelson. 1989. Isolation and characterization of pre-mRNA splicing mutants of Saccharomyces cerevisiae. Genes \& Dev. 3: 1206-1216.

Wang, C., K. Chua, W. Seghezzi, E. Lees, O. Gozani, and R. Reed. 1998. Phosphorylation of spliceosomal protein SAP 155 coupled with splicing catalysis. Genes \& Dev. 12: 1409-1414.

Will, C.L. and R. Luhrmann. 1997. Protein functions in premRNA splicing. Curr. Opin. Cell Biol. 9: 320-328.

Wu, S. and M.R. Green. 1997. Identification of a human protein that recognizes the $3^{\prime}$ splice site during the second step of pre-mRNA splicing. EMBO J. 16: 4421-4432.

Yean, S.L. and R.J. Lin. 1991. U4 small nuclear RNA dissociates from a yeast spliceosome and does not participate in the subsequent splicing reaction. Mol. Cell Biol. 11: 5571-5577.

Zahler, A.M., W.S. Lane, J.A. Stolk, and M.B. Roth. 1992. SR proteins: A conserved family of pre-mRNA splicing factors. Genes \& Dev. 6: 837-847.

Zahler, A.M., K.M. Neugebauer, W.S. Lane, and M.B. Roth. 1993. Distinct functions of SR proteins in alternative premRNA splicing. Science 260: 219-222.

Zhang, X. and B. Schwer. 1997. Functional and physical interaction between the yeast splicing factors Slu7 and Prp18. Nucleic Acids Res. 25: 2146-2152.

Zhou, Z. and R. Reed. 1998. Human homologs of yeast prp16 and prp17 reveal conservation of the mechanism for catalytic step II of pre-mRNA splicing. EMBO J. 17: 2095-2106. 


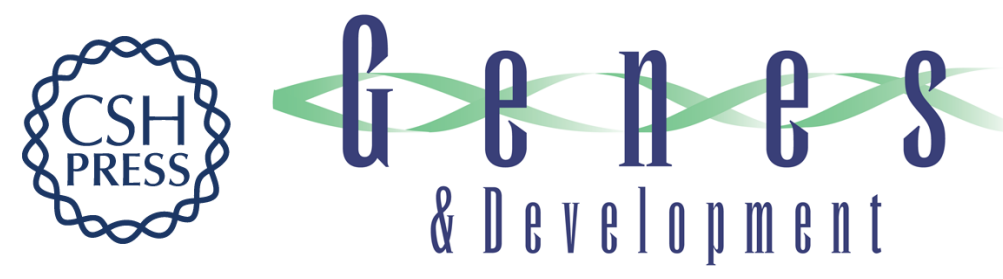

\section{Human step II splicing factor hSlu7 functions in restructuring the spliceosome between the catalytic steps of splicing}

Katrin Chua and Robin Reed

Genes Dev. 1999, 13:

References This article cites 59 articles, 32 of which can be accessed free at: http://genesdev.cshlp.org/content/13/7/841.full.htmI\#ref-list-1

License

Email Alerting

Service right corner of the article or click here.

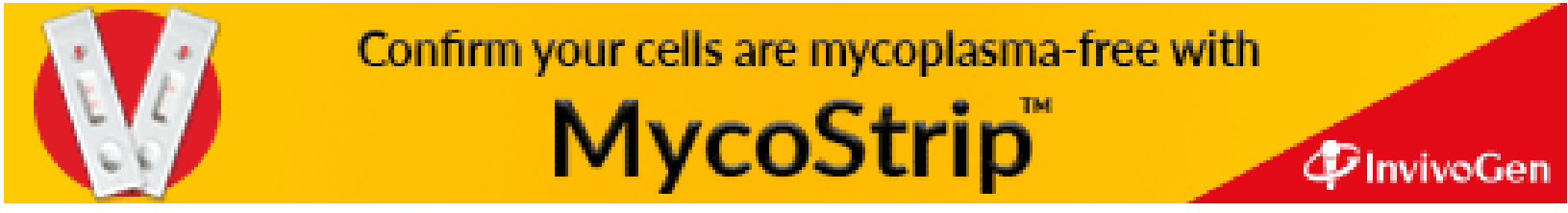

